\title{
Investigating the Educational Needs of Nursing Students Before and After Learning
}

\author{
Soghra Goliroshan ${ }^{1,3}$, Hamed Hoseinzadeh4, Sakineh Poorhosein Fookolaee ${ }^{5}$, \\ Parvin Aziznejadroshan ${ }^{\star 2,3}$, Soraya Khafri ${ }^{6}$ \\ ${ }^{1}$ Social Determinants of Health Research Center, Health Research Institute, Babol University of Medical Sciences, Babol, I.R.Iran \\ ${ }^{2}$ Non-Communicable Pediatric Disease Research Center, Health Research Institute, Babol University of Medical Sciences, Babol, I.R.Iran \\ ${ }^{3}$ Department of Nursing, School of Medicine, Babol University of Medical Sciences, Babol, I.R Iran \\ ${ }^{4}$ Master of Knowledge and Information Science, Ayatollah Rohani hospital, University of Medical Sciences, Babol, I.R.Iran \\ ${ }^{5}$ Faculty member, Department of Nursing, Sari Branch, Islamic Azad University, Sari, I.R.Iran \\ ${ }^{6}$ Department of Statistic and Epidmiology, School of Medicine, Babol University of Medical Sciences, Babol, I.R.Iran
}

\begin{abstract}
The results of educational needs assessment are widely used, including in the planning of curriculum, identification of issues and problems of individuals, assessment of comprehensive learning, enhancement and improvement of safety, and providing feedback to the individual or educational interventions in the organization. Therefore, this study was designed to determine the educational needs of nursing students before and after learning. This quasi-experimental study was performed on 65 nursing students in Babol University of Medical Sciences during the first semester of 2016-17. The data gathering tool was a researchermade questionnaire that was designed in two sections: demographic characteristics and educational needs questionnaire. Students were randomly divided into groups of 6-7. The validity of the tool was determined by the content validity method and its reliability was obtained through test-retest. Data were analyzed by descriptive and inferential statistics ( $t$-test, paired t-test, correlation, ANOVA) using SPSS software. The results showed that there is a significant difference between the mean scores of students before and after training $(P<0.001)$. Students have the highest level of ability to communicate with each other, training in the field of familiarity with the principles of serotyping with the best effectiveness, the ability to interpret blood and urine tests, and areas of ability to do certain things such as dressing, blood sampling and the ability to perform various injections were ranked respectively. The most important use of the results of the needs assessment is the development of educational programs for the purposes of the organization. Without a clear vision of the needs, efforts to develop organizational learning will waste valuable resources.
\end{abstract}

Keywords: Learning, educational needs, nursing students

\section{INTRODUCTION}

Clinical education provides the conditions for students to develop clinical classroom content and gain real

*Correspondence: Aziznejadroshan@yahoo.com

Parvin Aziznejadroshan, Non-Communicable Pediatric Disease Research Center, Health Research Institute, Babol University of Medical Sciences, Babol, I.R.Iran., Department of Nursing, School of Medicine, Babol

University of Medical Sciences, Babol, I.R Iran

Received: 24 March 2018 Accepted: 16 April 2018

Sleep and Hypnosis

Journal homepage:

www.sleepandhypnosis.org

ISSN: 2458-9101 (Online) experience on patients (Hemmati et al; 2012). The training process in the clinic is unique, since it is possible to carry out activities in a live position (Ironside et al; 2014). This competence is not gained through classroom education (Caliskan et al; 2012). Valizadeh writes that most newly graduated nurses do not have the skills to perform psycho-motor processes, and there is a great deal between the desirable situation and their status (Valizadeh et al; 2013). Maintaining the quality and safety of care is essential when meeting the patient's care needs and the need to ensure that nurses are qualified in clinical skills. Learning clinical skills is not only a prerequisite for 
providing safe care but also for facilitating clinical decision-making and interest in the profession. Among the obstacles to achieving this goal, there are shortcomings in the use of creative thinking and the process of problemsolving in the clinic by nurses (Lee et al; 2016). Some of the reasons are related to the design of the curriculum and curriculum (Rasool et al; 2007). Several studies have shown that a number of nursing faculties cannot develop the skills necessary to take on clinical skills, such as patient history, physical examination, and patient management. This has focused on the minds of many nursing researchers. The causes of this issue can be seen in the inconsistency between theoretical lessons and clinical work, the lack of clarity of the goals of clinical education, the stressful environment of the hospital, the low tendency of experienced instructors to attend clinical settings and the lack of coherence between instructors and students (Vahabi et al; 2011). In his research, Jamshidi (2012) showed that the most important clinical education problems of importance are: lack of clarity of duties of students in hospital departments, contradiction between educational goals and educational expectations of students, the inconsistency between theoretical and practical education, the lack of facilities for students, the weakness of students' ability to carry out care programs, the patient's and society's knowledge about the professional nurse, and lack of student support by the trainer (Jamshidi; 2012). Therefore, the clinical education programs and methods should be carefully reviewed so that they are designed and implemented in accordance with the learning environment in each clinical topic. According to the researchers, the time education can have the quality necessary for the professor and the student to know exactly about each other. For example, does the teacher know that the student who is in front of him is aware of how well? In other words, the first and most basic step before planning for training is the need to assess the strengths and weaknesses of that set. Identifying the most important needs is the basis for determining the goals and the appropriate framework for organizing human, financial and material resources and facilities (Zareiyan et al; 2005). The importance of educational needs assessment is that a curriculum based on educational needs has the ability to train qualified nurses (Bourgeois et al; 2011). Given the speed of knowledge development, it is necessary to use the knowledge of basic knowledge and to use modern knowledge of the world for all students to achieve the goal of developing health, care and treatment (Razavykia; 2012, Frazer et al; 2014). Therefore, the researchers decided to design a research aimed at investigating the effect of education based on educational needs on the clinical learning of undergraduate nursing students in the internship of internal-surgical internship(1), so that the findings of this study could be used to improve the quality of the training provided to other nursing students should be used.

\section{METHODS}

This is a quasi-experimental study that was done before and after 65 nursing students entering the year 2014. The research units consisted of 3rd semester nursing students of Babol University of Medical Sciences who completed the unit of nursing principles and skills and related apprenticeship in the previous year and in the first half of the academic year of 2016-2017, they received internal-surgical internship(1). The reason for choosing the students in the third semester also was that after students passed the unit of nursing principles and skills in the first semester and they became familiar with how to implement clinical methods. In the next semester (semester 2), the unit trains basic nursing principles and skills, it is only the main focus of their training in this course, familiarity with the hospital environment, communication with the patient, and the taking of a chart of vital signs on the patient's bedside and students do not find the opportunity to teach other clinical skills. In addition, summer holidays cause student interruptions in learning skills, so practically, students undergo internalsurgical internship(1), that are seriously involved in patient, case, cardiac, serum, droplet setting, dressing. Therefore, if a proper and correct instruction is implemented in this period, one can hope that the first step in the training of students has been taken in principle. The method of data collection in this study was based on a researcher questionnaire, which was divided into two 
sections: demographic characteristics and educational needs questionnaire was designed. The questionnaire of questionnaires consisted of 39 questions in 10 fields, which included, respectively: familiarity with the equipment and supplies (2 questions), the ability to communicate with the patient and the medical staff ( 2 questions), the ability to measure the vital signs ( 8 questions), the recognition of the types of serums and the ability to perform them (6 questions), familiarity with the file records (2 questions), correct way of giving the drug (3 questions), the ability to perform various injections ( 7 questions), the ability to do certain things such as changing dressing, blood sampling (4 questions), the ability to interpret blood and urine tests (3 questions), and finally the ability to write the nursing process and nursing (2 questions). Each of the questions was placed on a 5-point scale (Likert scale) so that the choice of the option always has a score of 5 , the most frequently used option is a score of 4 , an option sometimes a score of 3 , an option rarely score of 2 , and never received a score of 1. In this way, the overall range of scores between 35-175 was based on the 39 questions required in the questionnaire. The demographic characteristics of the students were evaluated in 4 questions including gender, mean of the previous year, the score obtained from the lessons of the principles and skills of nursing and the corresponding instructor during the internal-surgical internship(1), which was used to analyze the relationship between these variables and learning was investigated. The validity of the tool was based on content validity. The researcher designed the following questions after studying the texts and articles in order to identify the most important educational points for students at this stage and, with regard to the educational curriculum of the Ministry of Health and Medical Education, designed these questions. Then, these questions were shared with other faculty members of the Nursing Department of the university. After receiving their comments and making the necessary changes, the final questionnaire was designed $(C V R=0.74$ and $C R O=0.85)$. The reliability of the questionnaire was tested by a test-retest method in which 15 students participated with a two-week time interval and equaled $(r=0.94)$. After the approval of the project and the agreement between the university's educational and research deputy and the approval of the ethics committee and the approval of the hospital's directorate, the present study began. It was also assured to the students that, firstly, the information provided would remain completely confidential to the researchers, and secondly, it would not have any effect on the evaluation of the end of the course. At the beginning of the semester, the researcher set up a meeting for students, and, while expressing the goals and necessity of the project, invited interested students to participate in the research. Criteria for entering the research were the students' satisfaction to participate in the research and passing the units of nursing principles and skills and their teaching in the past and the criteria for leaving the research included the reluctance to continue to participate in the research and to have any previous clinical experience. A total of 65 students from 67 students were enrolled in the study and 2 students were excluded from the study because they were health workers and hospital staff. Then, the students were randomly divided into 10 groups at the discretion of the director of the nursing department and in groups of 6 to 7 girls and boys. All students completed the questionnaires on the first day of internship and the researchers, after collecting them, examined the strengths and weaknesses of each group's students and each group received training based on their educational needs during the three-week training period. Since the internalsurgical internship (1) is one unit in terms of the unit of training, training in 9 days of internship (3 weeks and the first 3 days from 7:30 to 13:30) in individually and in group, and according to the educational needs of the group and the curriculum approved by the Ministry of Health by 3 coaches, during which time the students' performance was monitored regularly. The most important thing during the internship period is where is the most need or disadvantage of nursing trainees? It is planned to be programmed. Students were also trained and supervised to understand what they learned. In the last training day, all groups completed the questionnaire again. The data before and after the course were analyzed using descriptive and analytical statistics (t-test, paired t-test, ANOVA, correlation) and analyzed using SPSS.20. 
It should be noted that the Correlation test was used to determine the correlation between the amount of clinical learning and some demographic characteristics, such as the mean score and the score of the theory of principles and nursing skills, and to determine the relationship between the amount of clinical learning with the trainers in the groups, ANOVA was used. To compare the clinical education of female students before and after intervention, male students before and after intervention were tested by paired t-test. Also t-test was used to compare the clinical education of both male and female students before and after intervention, as well as comparison of different domains before and after education. Also, $\mathrm{P}<0.05$ was considered as meaningful.

\section{FINDINGS}

Of the 65 students participating in this study, 36 students (55.4\%) were female and 29 students (44.6\%) were male. Also, the average of last year's female students was $14.67 \pm 1.57$ and the average of male students was $14.28 \pm 1.45$, and there was no statistically significant difference. The results showed that there is a significant difference between the mean scores of all students before and after the training $(\mathrm{P}<0.001)$. Also, the mean scores obtained before and after the education were significant in terms of gender, so that for groups, the girls and boys $(\mathrm{P}<0.001)$ were obtained. However, the mean scores of the two genders were not significant in the pretraining stage and after that (Table 1).

In order to investigate the relationship between some of the characteristics of students such as gender, clinical instructor, the mean score and the level of nursing principles and skills, with the clinical learning rate, the following results were obtained, as shown in Table 2 .

The results of the above table indicate that there is no significant relationship between gender and student's clinical learning $(P=0.89)$. Also, there is no significant relationship between the trainer and the level of learning $(P=0.22)$, which is not the difference between the performance of the coaches, and each coach has been equally effective in training them. Findings showed that there is a significant relationship between clinical learning and mean score and with increasing the mean, the amount of learning also increases, but this relationship is not significant and there is no strong correlation $(r=0.34$, $p=0.005$ ). Also, there was no significant relationship between the score of the nursing principles and skills, and the level of learning $(P=0.81)$.

The results of statistical tests showed a significant difference in all areas studied in this research, before and after training, which are presented in Table 3. Based on the

Table 1: Comparison of the average grades of students' need for education before and after the intervention

\begin{tabular}{lccc}
\hline Student Scores & $\begin{array}{c}\text { Before intervention } \\
\text { Mean } \pm \text { SD }\end{array}$ & $\begin{array}{c}\text { After intervention } \\
\text { Mean } \pm \text { SD }\end{array}$ & $\begin{array}{c}\text { Before and After } \\
\text { intervention }\end{array}$ \\
\hline Female & $122.47 \pm 14.33$ & $153.30 \pm 10.57$ & $* P<0.001$ \\
Male & $125.82 \pm 19.25$ & $156.31 \pm 10.96$ & $* P<0.001$ \\
Test result & $* * P=0.1$ & $\star * P=0.6$ & $* P<0.000$ \\
Total students & $123.96 \pm 16.67$ & $154.64 \pm 10.77$ & \\
\hline
\end{tabular}

* Paired $t$-test ${ }^{* *}$ t-test test

Table 2: Relationship between students' gender with clinical learning

\begin{tabular}{lcccccc}
\hline \multirow{2}{*}{$\begin{array}{l}\text { Demographic } \\
\text { characteristics }\end{array}$} & \multicolumn{2}{c}{ Gender } & \multicolumn{3}{c}{ Coach } & \multicolumn{2}{c}{\begin{tabular}{c} 
Nursing \\
Memale \\
\cline { 2 - 6 }
\end{tabular}} & $\begin{array}{c}\text { Male } \\
\text { Mean } \pm \text { SD }\end{array}$ & $\begin{array}{c}\text { First } \\
\text { Mean } \pm \text { SD }\end{array}$ & $\begin{array}{c}\text { Second } \\
\text { Mean } \pm \text { SD }\end{array}$ & $\begin{array}{c}\text { Third } \\
\text { Mean } \pm \text { SD }\end{array}$ & $\begin{array}{c}\text { Average } \\
\text { Principles and } \\
\text { Skills Score }\end{array}$ \\
\hline $\begin{array}{l}\text { * The amount of } \\
\text { clinical learning }\end{array}$ & $30.83 \pm 8.49$ & $30.48 \pm 11.70$ & $32.64 \pm 11.67$ & $29.40 \pm 8.81$ & $27.68 \pm 5.67$ & $r=0.34$ \\
$\begin{array}{l}\text { Test result } \\
\text { P-value }\end{array}$ & 0.89 & & 0.22 & & 0.005 \\
\hline
\end{tabular}

* Clinical learning rate: The difference between the mean scores before and after the training 
Table 3: The mean scores of students' response to the training needs questionnaire before and after training

\begin{tabular}{|c|c|c|c|c|}
\hline Areas & $\begin{array}{l}\text { Before training } \\
\text { Mean } \pm S D\end{array}$ & $\begin{array}{l}\text { After training } \\
\text { Mean } \pm S D\end{array}$ & P-value & $\begin{array}{l}\text { Difference } \\
\text { Mean } \pm \text { SD }\end{array}$ \\
\hline Introduction to Supplies and Equipment & $3.71 \pm 0.55$ & $4.40 \pm 0.44$ & $<0.001$ & $0.69 \pm 0.46$ \\
\hline The ability to communicate with the patient and the treatment staff & $4.30 \pm 0.57$ & $4.73 \pm 0.41$ & $<0.001$ & $0.43 \pm 0.45$ \\
\hline The ability to measure vital signs & $3.76 \pm 0.50$ & $4.39 \pm 0.38$ & $<0.001$ & $0.62 \pm 0.29$ \\
\hline Understanding Serums and Ability to Run It & $3.47 \pm 0.58$ & $4.71 \pm 0.28$ & $<0.001$ & $1.24 \pm 0.53$ \\
\hline Familiarity with file records & $3.68 \pm 0.61$ & $4.58 \pm 0.34$ & $<0.001$ & $0.90 \pm 0.47$ \\
\hline Proper drug execution & $3.61 \pm 0.74$ & $4.78 \pm 0.37$ & $<0.001$ & $1.17 \pm 0.71$ \\
\hline Ability to handle various injections & $3.38 \pm 1.02$ & $4.29 \pm 0.86$ & $<0.001$ & $0.90 \pm 0.51$ \\
\hline The ability to do certain things like dressing, dressing and etc. & $3.13 \pm 0.82$ & $3.94 \pm 0.75$ & $<0.001$ & $0.80 \pm 0.46$ \\
\hline Interpretation of blood and urine tests & $2.89 \pm 0.67$ & $3.80 \pm 0.63$ & $<0.001$ & $0.91 \pm 0.50$ \\
\hline Writing Nursing Process and Nursing Report & $3.40 \pm 0.62$ & $4.33 \pm 0.49$ & $<0.001$ & $0.93 \pm 0.54$ \\
\hline
\end{tabular}

results of the study, among the areas considered, the ability to communicate effectively with the patient and the medical staff with an average score of $4.30 \pm 0.57$ was the highest score that the students received before training, which indicated the students' ability in this area. In contrast, the ability to interpret the tests with an average score of $2.89 \pm 0.67$ was the lowest score that students received before training, which indicated their highest educational needs and also, the ability to do certain things such as blood transfusion, dressing with an average score of $3.13 \pm 0.67$, and the ability to perform injections with an average score of $3.38 \pm 1.04$, were in the next rank, indicating the most weakness of the students in these fields. The familiarity with the types of serum and awareness of the principles of serum therapy showed the most changes in the level of clinical learning, which indicates that education was most effective in this area. (Table 3 ).

\section{CONCLUSION}

The findings of this study showed that education based on identification of educational needs of students has increased their learning level. The results of Mansoorian et al, showed that nurses should develop their traditional roles in accordance with the needs of modern society. Nurses' awareness of their work can be seen in the clinical setting. Nursing education should prepare students for their professional tasks (Mansoorian et al; 2015). The results of this study are consistent with the results of Patel et al. Their study showed that training has a positive effect on the level of knowledge and clinical practice of medical students in performing procedures such as catheterization and tracheal tube in hospital settings (Patel et al; 2008). The findings of Haj Bagheri et al, also showed that the average score of nursing students' learning in clinical education was based on the nursing process and group discussion compared to the traditional method (Hajbagheri et al; 2012). The results of Khalifezadeh et al, study showed that there is a significant difference between the mean of interpersonal, professional and communication skills before and after the implementation of the clinical monitoring and supervision program (Khalifezadeh et al; 2001). Safari and Salsali also found that training nurses improves the efficiency and quality of care (Safari et al; 2004). The results of the study by Madhavanprabhakaran et al, showed that pre-clinical simulated education increases clinical learning in nursing students (Madhavanprabhakaran et al; 2015).

Based on the results of this study, students had the highest average score in terms of the ability to communicate effectively with the patient and the treatment staff, which showed their highest level of ability in this field. In their research, Navabi et al, found that the performance of nursing students in relation to patient was moderate (Navabi et al; 2003). The results of Heaven et $\mathrm{al}$, showed that education increases the level of nurses' knowledge of communication skills, but should be accompanied by an intervention in the clinical setting, otherwise it will have little impact. This means that clinical supervision, along with providing support to nurses, can 
increase the effectiveness of educational skills (Heaven et al; 2006). The need for communication is because the nurse is the person who needs to play a role in a daily contact with the patient so that he can provide his professional services. The nurse needs to be properly observed, evaluated and responsive to the needs of patients, and such tasks need to have an understanding and skill in communicating.

The results of this study showed that the field of interpretation of experiments has the highest educational needs. Considering that nurses should have sufficient knowledge of the interpretation of the tests to report abnormal cases to the doctor quickly, more attention and training of students in this field should be taken into account. These results are in line with the results of Khazaei and Salehi. In their study, they found that the educational needs of nursing students in clinical courses such as the interpretation of tests and CPR training were very high (Khazaei et al; 2007). In a study by Nasiriani et al., new nursing graduates reported moderate levels of laboratory tests (Nasiriani et al; 2006). Also, the results of the Tabeei and colleagues study showed that the level of awareness of internal, surgical, pediatric and gynecologic subjects was less than or equal to $50 \%$ in the laboratory tests, which confirmed the necessity of reviewing the medical students' curriculum (Tabeei et al; 2008). Sabeti and colleagues also showed that $56.7 \%$ of the students in the last semester of nursing skills were skilled and interpreted for diagnostic tests (Sabeti et al; 2011).

Two other areas that are most in need of education in the following categories are the ability to perform certain tasks, such as blood sampling and dressing, and the ability to perform various injections. The study by Golalipour et al, showed that $71.7 \%$ of medical students did not have the skills to do injections and $74.2 \%$ lacked the skill in wound dressing (Golalipour et al; 2002). In another study, the results indicated that the level of knowledge and practice of medical students before the course was in areas such as investigation of vital signs, low injections and increased after the implementation of the educational program (Mardani et al; 2010). In Sabeti research and colleagues, full knowledge of the last term nursing students was reported in the sample of blood transfusion (78.3\%).
While this skill was about $35 \%$ for arterial blood samples, this indicates a lack of student skills. Therefore, considering that one of the tasks of nurses is taking blood samples for diagnostic tests, nursing educators should be trained on the patient's bedside at appropriate opportunities.

The results of the present study indicated that after the implementation of the training, the most changes in the level of clinical learning are related to the understanding of the types of serums and the ability to perform them by students. The results of the study, Gholizadeh Pasha et al, showed that nurses' knowledge about serum is so benign. This indicates that the graduate nurses did not acquire familiarity and skills at the time of their education (Gholizadeh Pasha et al; 2003). Razavykia states in his study that $53.5 \%$ of students are able to implement the lessons learned on the patient's bedside. This indicates the practical weakness of the students in the clinical field (Razavykia; 2012). According to Vahabi et $\mathrm{al}$, research, $54.23 \%$ of nursing students assessed the status of clinical education in terms of achievement of goals and educational program at moderate level and $80 \%$ of instructors. This significant difference may be due to the fact that most coaches see the implementation of all their tasks as providing a classroom lesson to college and students, while students perceive the lack of commitment of the instructors to precise and thorough implementation of the lesson plan and apprenticeship timetable, students see it as an excuse for not paying attention to fulfilling their obligations (Vahabi et al; 2011).

The results of this study showed that in order to improve the level of knowledge and clinical performance of students, education should be based on identifying their educational needs so that they can increase the level of student learning. The results of this study showed that in order to improve the level of knowledge and clinical performance of students, education should be based on identifying their educational needs so that they can increase the level of student learning. Therefore, it is recommended that educational centers design a framework or list of goals and educational needs for each nursing course, in order to identify the topics that should be taught during each period, the ultimate goal of student learning and satisfaction with the course is to be achieved. 
Acknowledgement: I am grateful to all the distinguished members of the faculty of the Babol Nursing Faculty and the dear students who helped us in this study. Conflict of interests: None declared.

\section{References}

Adib-Hajbaghery, M., Mir Bagher, N., Heidari, S. (2012). Clinical nursing education based on nursing process and group discussion. Iranian Journal of Medical Education, 11(7), 728-34.

Bourgeois SH, Drayton N. Ann-Marie Brown. (2011). An innovative model of supportive clinical teaching and learning for undergraduate nursing students: The cluster model. Nurse Education in Practice, 11(2), 114-18.

Caliskan, N., Ozturk, D., Gocmen Baykara, Z., Korkut, H., Karadag, A. (2012). The effect of periodic training on the clinical application of nursing students' psychomotor skills. ProcediaSocial and Behavioral Sciences, 47, 786 -91.

Frazer, K., Connolly, M., Naughton, C., Kow, V. (2014). Identifying clinical learning needs using structured group feedback: First year evaluation of pre-registration nursing and midwifery degree programmers. Nurse Education Today, 34(7), 1104-08.

Gholizadeh Pasha, R., Hassanjani Roshan, M. (2003). Knowledge of nurses about using vials and electrolytes, Tehran and Babol Medical Universities. Journal Of Babol University Of Medical Sciences, 5 (5), 52-5.

Golalipour, M. J., KHodabakhshi, B., Vaghari, G. H. (2002). Evaluation of practical skills of clinical medical student in Gorgan University. Iranian Journal of Medical Education, 2, 26 26.

Habibi, H., Raiesifar, A., Khaghanizade, M., Mahmudi, H., Seyed Mazhari, M., Ebadi, A. (2015). The effect of applying direct observation of procedural skills (DOPS) on nursing students' clinical skills: a randomized clinical trial. Global Journal of Health Science; 7( 7):17-21.

Heaven, C., Clegg, J., \& Maguire, P. (2006). Transfer of communication skills training from workshop to workplace: the impact of clinical supervision. Patient Education and Counseling, 60(3), $313-25$.

Hemmati Maslakpak, M., Khalilzadeh, H. (2012). Nursing students' perspectives on effective clinical education: a qualitative study. Iranian Journal of Medical Education, 11 (7):718-27.

Ironside, P. M. , Mc Nelis, A. M., Ebright, P., (2014). Clinical education in nursing: Rethinking learning in practice settings. Nurse Outlook, 62(3):185-91.

Jamshidi, L. (2012). The challenges of clinical teaching in nursing skills and lifelong learning from the standpoint of nursing students and educators. Procedia-Social and Behavioral Sciences, 46, $3335-8$

Khalifezadeh, A., Salehi, S., Hassanzadeh, A. (2001). The effects of clinical supervision program application on nursing. Iranian Journal of Medical Education, 1 (3), 37-41.

Khazaei, T., \& Salehi, F. (2007). Evaluation of the complementary educational needs in the view of the nursing students of the University of Medical sciences of Brigand. Birjand University of Medical Sciences, 4(1-4), 47-52.

Lee, N. J, Chae, S. M, Kim, H, Lee, J. H, Min, H. J, Park, D. E. (2016). Mobile-based video learning outcomes in clinical nursing skill education a randomized controlled trial. Computers, Informatics, Nursing 34(1):8-16. doi: 10.1097/ CIN.0000000000000183.
Informed consent: Informed consent was obtained from all the participants included in the study.

Funding: This study was financially supported by Babol University of Medical Sciences (Grant Number: 9337623).

Madhavanprabhakaran, G., Al-Khasawneh, E. Wittmann, L. (2015). Perceived benefits of pre-clinical simulation-based training on clinical learning outcomes among omani undergraduate nursing students. Sultan Qaboos University Medical Journal, 15(1), 105-11.

Mansoorian, M. R., Hosseiny, M. H, Khosravan, S. H., Alami, A., Alaviani, M. (2015). Comparing the effects of objective structured assessment of technical skills (OSATS) and traditional method on learning of students. Nurse Midwifery Study; 4(2),1-5.

Mardani, M., Shams-khoramabadi, M., Mosadagh, A. H., Rezapour, S. (2010); The impact of the training program "The acquisition of clinical skills in emergency" on learning of medical students. Quarterly Research journal of Lorestan University of Medical Sciences, 12(3), 45-50.

Nasiriani, K., Farnia, F., Salimi, T., Shahbazi, L., \& Motavasselian, M. (2006). Nursing graduates' self-assessment of their clinical skills acquired in medical-surgical wards. Iranian Journal of Medical Education, 6(1), 93-100.

Navabi, N., \& Asri, M. (2003). Practice rate of nursing students about communication with patients (Tonekabon Shahid Rajai Hospital; 2002-2003). Journal Of Babol University Of Medical Sciences, 5(5), 48-51.

Patel, M., Oosthuizen, G., Child, S., Windsor, J. A. (2008). Training effect of skills courses on confidence of junior doctors performing clinical procedures. Journal of the New Zealand Medical Association, 121,1275-9.

Rasool, G. H., Rawaf, S. (2007). Learning style preferences of undergraduate nursing students. Nursing Standard, 21(32):35-41.

Razavykia, M. (2012). Evaluation of the educational needs in the nursing students of the Islamic Azad University of Hamedan 2010. Procedia - Social and Behavioral Sciences, 31, 564-67.

Sabeti, F., Akbari-Nassaji, N., Haghighy Zadeh, M. H. (2011). Nursing students' self-assessment regarding clinical skills achievement in Ahvazjundishapur University of Medical Sciences. Iranian Journal of Medical Education, 11(5), 506-15.

Safari, M., Salsali, M., Ghofranipour, F. (2004). Effect of nursing education through group discussion on the quality of nursing care of patients with myocardial infarction. Annals of Military and Health Sciences Research, 2 (4), 437-41.

Tabeei, H., Safaeia, A., \& Tabeei, Z. (2008). Clinical evaluation of medical assistants skills of clinical laboratory tests. Journal of Medical Council of Iran, 26(2), 201-4.

Vahabi, S., Ebadi, A., Rahmani, R., Tavallaei, A., Khatouni, A. R., Tadrisi, S. D., ... \& Heydaranlou, E. (2011). Comparison of the status of clinical education in the views of nursing educators and students. Education Strategies in Medical Sciences, 3(4), 179-182.

Valizadeh, L.., Amini, A., Fathi-Azar, E., Ghiasvandian, S. H., Akbarzadeh, B. (2013). The effect of simulation teaching on baccalaureate nursing students' self-confidence related to peripheral venous catheterization in children: a randomized trial. Journal of Caring Sciences, 2(2): 157-64.

Zareiyan Jahromi, A., Ahmadi, F. (2005). Learning needs assessment in bachelor of nursing: a qualitative research. Iranian Journal of Medical Education, 5(2), 86-98. 